\title{
Differential Effects of Glycine Betaine and Spermidine on Osmotic Adjustment and Antioxidant Defense Contributing to Improved Drought Tolerance in Creeping Bentgrass
}

\author{
Nanqing Liu \\ College of Agro-Grassland Science, Nanjing Agricultural University, Nanjing 210095, People's \\ Republic of China; and Department of Landscape Architecture, Jiangsu Turfgrass Germplasm \\ Resource Center, Polytechnic College of Agriculture and Forestry, Jurong 212400, People's Republic \\ of China \\ Shaoyan Lin \\ State Key Laboratory of Crop Genetics and Enhancement, Nanjing Agricultural University, Nanjing \\ 210095, People's Republic of China \\ Bingru Huang1
Department of Plant Biology and Pathology, Rutgers University, New Brunswick, NJ 08901
}

AdDitional INDEX words. Agrostis stolonifera, osmoregulants, water stress, enzyme activity

\begin{abstract}
Glycine betaine (GB) and spermidine (Spd) are known to play roles in plant adaptation to stresses that induce dehydration, including drought stress. The objectives of this study were to examine whether improved drought tolerance by exogenous application of GB or Spd is associated with the increases in the endogenous accumulation of those solutes under drought stress in cool-season turfgrass species, and to determine the relative effects of those solutes on osmotic adjustment (OA) and antioxidant metabolism for improving drought tolerance. Creeping bentgrass (Agrostis stolonifera cv. Penncross) plants were treated with $200 \mathrm{~mm}$ GB or $0.1 \mathrm{~mm}$ Spd for 3 weeks by weekly foliar application before the exposure to drought stress; those plants were subsequently subjected to drought stress by withholding irrigation. The endogenous content of GB and Spd increased significantly through the exogenous application of either compound, to a greater magnitude for GB. The comparison of GB- or Spd-treated plants to untreated plants exposed to drought stress for growth [turf quality (TQ)] and physiological responses (water relations, membrane stability, and antioxidant metabolism) demonstrated that both compounds led to significant improvement in drought tolerance in creeping bentgrass. The improved drought tolerance by exogenous GB could be due to its contribution to $O A$ by significant accumulation of endogenous $G B$, and activation of antioxidant enzymes with the greatest effects on ascorbate peroxidase (APX). Exogenous Spd did not cause increases in leaf OA despite of the increased endogenous accumulation, but significantly enhanced antioxidant enzyme activities, with the most pronounced effects on catalase (CAT). This study demonstrated that GB and Spd had different effects on OA and activated different antioxidant defense pathways, protecting plants from drought damages in creeping bentgrass.
\end{abstract}

Drought injury in turfgrass is characterized by leaf desiccation, which is associated with excessive water loss from leaves and disruption of cell membranes due to oxidative stress induced by water deficit (Nilsen and Orcutt, 1996). One mechanism for plants to survive drought stress is OA through accumulating solutes that allow plants to maintain leaf cellular hydration and sustain metabolic activities during drought stress, and OA level is positively correlated to whole-plant drought tolerance in many plant species, including turfgrasses (DaCosta and Huang, 2006; Qian and Fry, 1997; White et al., 1992). Another strategy to maintain survival of leaves from drought damages is the activation of antioxidant defense systems, which

Received for publication 17 Oct. 2016. Accepted for publication 21 Nov. 2016. We thank Jiang Su Education Commission for financial support for Nanqiing Liu to conduct the collaborative research project at Rutgers University. We wish to thank Patrick Burgess and Shaoyan Lin for assistance in plant material preparation and technical support. We also wish to thank Patrick Burgess and Stephanie Rossi for critical review of the manuscript.

${ }^{1}$ Corresponding author. E-mail: huang@aesop.rutgers.edu. involve antioxidant enzymes, such as superoxide dismutase (SOD), peroxidase (POD), CAT, and APX, to scavenge excessive reactive oxygen species accumulated in plants during drought stress (Nilsen and Orcutt, 1996).

One convenient and effective approach to protecting plants from drought damages is exogenous application or enhanced endogenous production of some organic solutes that may enhance OA and antioxidant defense. Glycine betaine, a quaternary ammonium compound, is known to accumulate in chloroplasts in response to dehydration under drought or salinity stress, but the endogenous amount of GB may be not sufficient to ameliorate the adverse effects of dehydration stress in many plant species (Ashraf and Foolad, 2007; Rhodes and Hanson, 1993). Therefore, exogenous application of GB to lowaccumulating or nonaccumulating plants is greatly beneficial for plant defense against the adverse effects of environmental stresses, but the effectiveness may vary with plant species due to the difference in endogenous amount of GB in the plant species (Ashraf and Foolad, 2007; Farooq et al., 2008; Gupta et al., 2013). A number of studies reported that GB-enhanced 
drought tolerance is due to its involvement in OA in some plant species (Ashraf and Foolad, 2007; Burgess and Huang, 2013), whereas other studies found that GB-induced salinity tolerance was related to the enhanced antioxidant defense systems (Demiral and Türkan, 2004; Hoque et al., 2008; Okuma et al., 2004). Polyamines, including Spd, putrescine, and spermine, are ubiquitous aliphatic amines, which tend to accumulate in response to dehydration stress and have also been found to play positive roles in improving drought tolerance; among the three major polyamines, Spd is more effective in many cases (Bouchereau et al., 1999; Yamaguchi et al., 2007). The beneficial effects of polyamines are manifested by the reduction in electrolyte leakage (EL) (Amri and Shahsavar, 2010), increases in relative water content (RWC) and photosynthetic capability (Yin et al., 2014), as well as the activity of major antioxidant enzymes (Amri and Shahsavar, 2010; Kubiś, 2003).

Creeping bentgrass is drought-sensitive cool-season grass species widely used as turfgrass in high maintenance areas. This species may naturally produce low quantities of GB and Spd, and therefore, exogenous application may enhance drought tolerance by enhancing endogenous accumulation of these metabolites through influencing OA or antioxidant defense. Previous studies on creeping bentgrass reported the promotive effects of exogenous GB or Spd on drought tolerance (Burgess and Huang, 2013; Shukla et al., 2015; Yang et al., 2012), but whether it was related to the induction of endogenous accumulation of those solutes was not well documented. Despite of the known beneficial effects of GB and Spd in different plant species, whether the positive effects of GB and Spd are mainly due to their involvement in OA or/and antioxidant defense is not well understood. The objectives of this study were 1) to determine whether improved drought tolerance by exogenous application of GB or Spd is associated with the increases in the endogenous accumulation of those solutes under drought stress in creeping bentgrass, and 2) to determine the relative effects of those solutes on OA and antioxidant metabolism for improving drought tolerance in creeping bentgrass.

\section{Materials and Methods}

Plant materials and growth Conditions. Sods of creeping bentgrass (cv. Penncross) were collected from field plots at the turfgrass research farm of Rutgers University in North Brunswick, NJ. Sods were washed free of soil with water, and transplanted into polyvinyl chloride (PVC) pots $(10 \mathrm{~cm} \mathrm{di-}$ ameter, $40 \mathrm{~cm}$ height) filled with a sterilized mixture of sand and loam soil (fine-loamy, mixed, mesic, Typic Hapludult) (1:3 $\mathrm{v} / \mathrm{v})$. A nylon screen covered the bottom of each PVC pot to contain the soil and allow for drainage of water from the pots.

Plants were maintained in the greenhouse at Rutgers University under 10 - to $12-\mathrm{h}$ (varying with the weather) natural light conditions with supplemental lighting provided by sodium lamp, and average temperatures of $21 / 13^{\circ} \mathrm{C}$ (day/night) for $60 \mathrm{~d}$ during 6 Apr. to 6 May 2014. Plants were watered three times per week until drainage occurred from the bottom of the pots at each time of irrigation to maintain soil moisture at the pot capacity, and fertilized weekly with half-strength Hoagland's solution (Hoagland and Arnon, 1950). All plants were hand clipped weekly at 3 to $4 \mathrm{~cm}$ height. After $60-\mathrm{d}$ of plant establishment in the greenhouse, plants were moved to growth chambers that were controlled at $20 / 15^{\circ} \mathrm{C}$ (day/night), $12-\mathrm{h}$ photoperiod at photosynthetically active radiation of
$650 \mu \mathrm{mol} \cdot \mathrm{m}^{-2} \cdot \mathrm{s}^{-1}$, and $75 \%$ relative humidity. Plants were allowed to acclimate to growth chamber conditions for $14 \mathrm{~d}$ before treatments were imposed.

Treatments AND EXPERIMental Design. Plants were sprayed with GB at $200 \mathrm{~mm}$ and Spd at $0.1 \mathrm{~mm}$ weekly for 3 weeks from 20 May to 11 June 2014, and then subsequently exposed to drought stress for $13 \mathrm{~d}$ by withholding irrigation, starting on 12 June 2014 ( $0 \mathrm{~d}$ of drought stress). The concentration used for each compound was selected based on a preliminary study, which was found to be most effective in enhancing turf performance under drought stress. For each treatment, sufficient solution $(50 \mathrm{~mL})$ was sprayed to evenly cover the turf canopy $\left(78 \mathrm{~cm}^{2}\right.$ diameter) without dripping into the soil. Plants sprayed with water and exposed to drought stress served as the untreated control. Plants sprayed with water and maintained under well-watered conditions were used as the well-watered control.

The experimental design was a complete randomized design with four treatments (drought $+\mathrm{GB}$, drought $+\mathrm{Spd}$, drought, and watered control) and each treatment had four pots of plants as four replicates. Four replicates of each treatment were placed in four growth chambers, with one replicate of each treatment being placed in one growth chamber. Plants were relocated every $3 \mathrm{~d}$ among growth chambers to avoid potential confounding effects of variable environmental conditions in different chambers.

Physiological analysis. All physiological measurements were made on $0,5,9$, and $13 \mathrm{~d}$ of drought stress. Turf quality was visually rated based on turf color and degree of leaf wilting on a scale of 1 to 9 (a rating of 1 indicated a completely desiccated brown turf canopy and a rating of 9 representing fully turgid, green, dense, and healthy turf canopy); TQ of 6.0 is considered as the minimal acceptable level (Turgeon, 2008).

For the measurement of leaf RWC, leaf samples were detached from the turfgrass and immediately weighed for fresh weight $(\mathrm{FW})$. Leaf samples were placed into covered centrifuge tubes and soaked in water at $4{ }^{\circ} \mathrm{C}$. After $\approx 20 \mathrm{~h}$, the leaf samples reach full hydration, and were taken out of tubes, then were blotted dry and weighed immediately for turgid weight (TW). DW is leaf dry weight after oven-drying the leaf samples for $72 \mathrm{~h}$ at $80^{\circ} \mathrm{C}$. Leaf RWC was calculated as: $100 \times[(\mathrm{FW}-\mathrm{DW}) /$ (TW - DW)].

Leaf EL measurement was performed to evaluate cellular membrane stability (Blum and Ebercon, 1981). Leaf samples $(\approx 0.15 \mathrm{~g})$ were cut to 0.5 -cm-long segments, immersed in 25 to $30 \mathrm{~mL}$ of deionized water, and placed on a conical shaker for 12-h incubation. The initial level of EL $\left(C_{\mathrm{i}}\right)$ was measured using a conductance meter (Model 132; YSI, Yellow Springs, $\mathrm{OH})$. Leaf samples were then killed at $120{ }^{\circ} \mathrm{C}$ for $15 \mathrm{~min}$ in an autoclave, incubated on the conical shaker for $12 \mathrm{~h}$, and final level of conductance of the incubation solution $\left(C_{\max }\right)$ was measured. Leaf EL was calculated as $\left(C_{\mathrm{i}} / C_{\max }\right) \times 100$ (Blum and Ebercon, 1981).

Leaf OA was determined as the difference in leaf osmotic potential at full turgor $\left(\Psi_{\pi 100}\right)$ between well-watered and drought-stressed plants (Qian and Fry, 1997). Leaf $\Psi_{\pi 100}$ was determined after soaking leaves in water for $8 \mathrm{~h}$ until reaching full hydration. Turgid leaf samples were frozen in liquid nitrogen and subsequently stored at $-20{ }^{\circ} \mathrm{C}$ until analysis of $\Psi_{\pi 100}$. Frozen leaf samples were thawed and cell sap was pressed from leaves using a laboratory press (Fred S. Carver, Wabash, IN), which was subsequently analyzed for osmolality 
(C) using a vapor pressure osmometer (Vapro model 5520; Wescor, Logan, UT). Osmolality of cell sap was converted from $\mathrm{C}$ (millimoles per kilogram) to $\Psi_{\pi}(\mathrm{MPa})$ using the formula: $\mathrm{MPa}=-\mathrm{C} \times 2.58 \times 10^{-3}$.

Quantification of endogenous Content of GB AND SPD. About 1-2 $g$ fresh leaves from each replicate for each treatment were sampled for the measurement of the endogenous content of GB and Spd at $9 \mathrm{~d}$ of drought stress when physiological effects were most significant.

The content of Spd was determined according to the method described by Liu et al. (2002). Dry leaf tissue powder $(0.1 \mathrm{~g})$ was extracted in $2 \mathrm{~mL}$ of precooled perchloric acid, ice bath for $60 \mathrm{~min}$, and centrifuged at $15,000 \mathrm{~g}_{\mathrm{n}}$ for $30 \mathrm{~min}$. The supernatant was transferred into a centrifugal tube and stored at $-20^{\circ} \mathrm{C}$. Polyamines (PA) contained in the supernatant were subjected to a benzoylation reaction in the alkaline medium. Benzoyl PA derivatives were extracted by diethyl ether. Ether fraction was evaporated to dryness and dissolved in methanol. High-performance liquid chromatography (HPLC) was performed on a liquid chromatograph (Thermo Fisher Scientific, Waltham, MA) using a silica column [5 $\mu \mathrm{m}, 250 \times 4.6 \mathrm{~mm}$ (Diamonsil ${ }^{\circledR} \mathrm{C} 18(2)$; Dikma Technologies, Lake Forest, CA)]; $10 \mu \mathrm{L}$ of benzoyl polyamine in methanol was injected into an autosampler (Surveyor; Thermo Fisher Scientific) every $35 \mathrm{~min}$. Samples were eluted from the column with $70 \%$ methanol and with a temperature maintained at $30{ }^{\circ} \mathrm{C}$, and the flow rate was $0.7 \mathrm{~mL} \cdot \mathrm{min}^{-1}$. The Spd peaks were detected with an ultraviolet detector at $230 \mathrm{~nm}$. Spd content was quantified using an internal standard.

GB was determined using the method described by Wang et al. (2010). Dry leaf tissue powder $(0.1 \mathrm{~g})$ was extracted in $12.5 \mathrm{~mL}$ water, shaken for $30 \mathrm{~min}$, and then centrifuged at $14,000 g_{\mathrm{n}}$ for $5 \mathrm{~min}$. The supernatant was filtered through glass fiber filters, and filtrate was transferred to solid-phase cartridges [150 mg/6 mL (Poly-Sery MCX; Organomation, Berlin, MA)]. Then extraction cartridges were rinsed by methanol/water $(85: 15 \mathrm{v} / \mathrm{v})$ and methanol. Elution was completed by using a mixture of ammonia water/methanol $(5: 95 \mathrm{v} / \mathrm{v})$ twice. The residue was condensed dry and diluted with acetonitrile/water $(50 \% \mathrm{v} / \mathrm{v})$ and filtered through a $0.45-\mu \mathrm{m}$ membrane (Millipore; Merck, Darmstadt, Germany) for further analysis in HPLC. Solution of acetonitrile/water $(50 \% \mathrm{v} / \mathrm{v})$ was the mobile phase for HPLC analyses. GB was analyzed and quantified by HPLC using a hydrophilic interaction liquid chromatography silica column [5 $\mu \mathrm{m}, 4.6 \times 150 \mathrm{~mm}$ (Atlantis; Waters Corp., Milford, MA)]. The peak areas were integrated and compared with standard curve constructed with standard of GB.

ANALYSIS OF ANTIOXIDANT ENZYMe ACTIVITY. Fresh leaves were sampled for the measurement of antioxidant enzyme activity at $9 \mathrm{~d}$ of drought stress when physiological effects were most significant. About $0.5-1.0 \mathrm{~g}$ leaf of fresh leaf tissue was randomly sampled from each plant, frozen in liquid nitrogen, and stored at $-80{ }^{\circ} \mathrm{C}$ for further analysis. Extraction of antioxidant enzymes and malondialdehyde (MDA) was performed as previously described by Xu and Huang (2004). MDA is the final product of membrane lipid peroxidation, which is quantified as an indication of oxidative damages. For enzymes and MDA extraction, the frozen samples were homogenized with $7 \mathrm{~mL}$ of $50 \mathrm{~mm}$ phosphate buffer solution ( $\mathrm{pH} 7.0$ ), ground in a mortar on ice, and centrifuged at 20,000 $g_{n}$ at $4{ }^{\circ} \mathrm{C}$ for $25 \mathrm{~min}$. The supernatant was used to evaluate enzyme activity and MDA content.
The activity of SOD was measured according to the method of Zhang and Kirkham (1996) and Xu and Huang (2004). One unit of SOD activity was defined as the amount of SOD required to cause $50 \%$ inhibition of nitroblue-tetrazolium reduction at $560 \mathrm{~nm} \cdot \mathrm{min}^{-1}$. The activities of CAT, APX, and POD were determined based on the method of Chance et al. (1955) and Xu and Huang (2004). Enzyme activities were based on the absorbance change of the reaction solution per minute at a given wavelength for each enzyme: CAT at $240 \mathrm{~nm}$, APX at $290 \mathrm{~nm}$, and POD at $470 \mathrm{~nm}$. MDA content was measured at 532 and $600 \mathrm{~nm}$ after reaction of the extraction solution with trichloroacetic acid and thiobarbituric acid using the method of Dhindsa et al. (1981). The formula used for calculation of MDA content was the absorbance at $600 \mathrm{~nm}\left(\mathrm{~A}_{600}\right)$ subtracted from the absorbance at $532 \mathrm{~nm}\left(\mathrm{~A}_{532}\right)$ multiplied by the extinction coefficient of $155 \mathrm{~mm} \mathrm{~mm}^{-1} \cdot \mathrm{cm}^{-1}$ for MDA (Heath and Packer, 1968). All reaction solutions, nonreacted control solutions, and standards were analyzed at a given wavelength with a spectrophotometer (Spectronic Instruments, New York, NY).

Statistical anAlysis. Statistical significance of data was tested using the analysis of variance procedure (SAS, version 9.0; SAS Institute, Cary, NC). Differences between treatment means were separated by Fisher's protected least significant difference test at the $0.05 P$ level.

\section{Results and Discussion}

Turf quality is a widely used parameter to evaluate overall turfgrass performance (Turgeon, 2008). In this study, TQ was maintained between 8.0 and 9.0 throughout the experimental period in the well-watered control, but exhibited a steady decline with the drought duration regardless of chemical treatments (Fig. 1). The application of GB or Spd resulted in increases in TQ compared with the untreated plants at 9 and $13 \mathrm{~d}$ of drought stress. These data suggested that exogenous application of GB

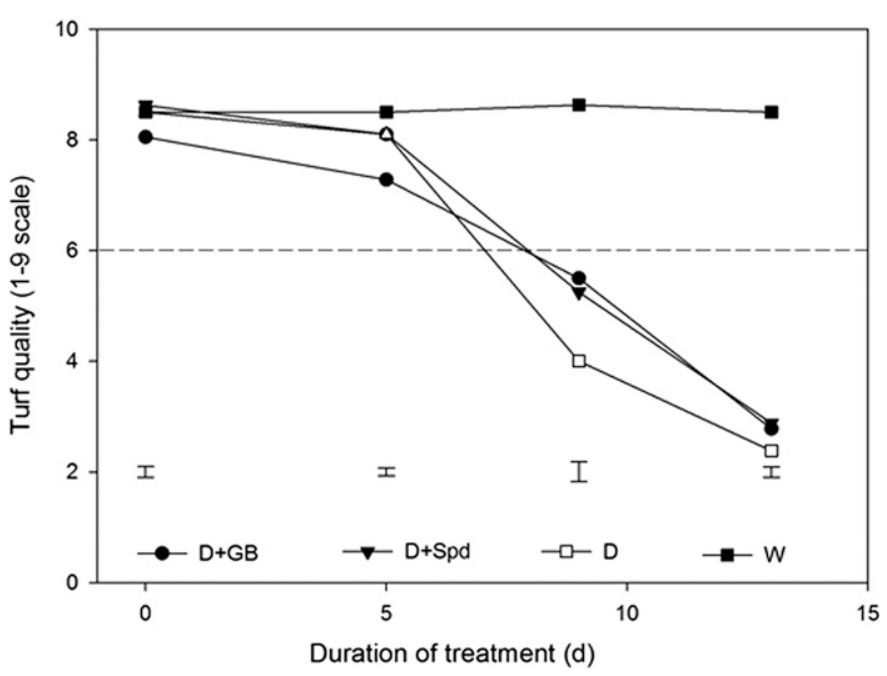

Fig. 1. Turf quality (TQ) of creeping bentgrass under well-watered (W) and drought stress without (D) and with glycine betaine (D + GB) or spermidine $(\mathrm{Spd} ; \mathrm{D}+\mathrm{Spd})$ treatments. Drought stress was imposed on 12 June $2014(0 \mathrm{~d})$. TQ rated on the scale of 1-9 with $1=$ completely desiccated brown turf canopy and $9=$ fully turgid, green, dense, and healthy turf canopy. The dash line indicates the minimal acceptable TQ of 6.0. Vertical bars on the top are least significant difference values $(P=0.05)$ for comparisons at a given day of treatment. 
or Spd promoted overall turf performance under drought stress. Previous studies that have examined the effects of individual compounds in different plant species found that TQ was improved under drought stress by GB in kentucky bluegrass [Poa pratensis $(100 \mathrm{~mm})]$ and creeping bentgrass $(200 \mathrm{~mm})$ (Burgess and Huang, 2013; Yang et al., 2012) and by polyamines [5 mM Spd in bermudagrass (Cynodon dactylon) (Shi et al., 2013), 500 or $750 \mu \mathrm{M}$ (Shukla et al., 2015)]. Our study found that foliar application of GB at $200 \mathrm{~mm}$ and Spd at $0.1 \mathrm{~mm}$ effectively improved TQ of creeping bentgrass exposed to drought stress. The results in this study with creeping bentgrass together with previous studies in other turfgrass species suggested that the effective doses of GB or Spd could vary with plant species.

Maintaining adequate water status in plants is critically important for maintaining high TQ and plant survival under drought stress (Rachmilevitch et al., 2006). In our study, leaf RWC was maintained at above $87.00 \%$ in the well-watered control throughout the experimental period (Fig. 2). All treatments exhibited a sharp decline in RWC below the wellwatered control level during drought stress, but plants treated with GB and Spd showed significantly higher RWC than that of the untreated plants within $9 \mathrm{~d}$ of drought stress. However, Shukla et al. (2015) found foliar application of Spd (at 500 or $750 \mu \mathrm{M}$ ) had no significant effects on water relations of creeping bentgrass under drought stress. Our results suggested that exogenous application of GB or Spd could facilitate water retention in leaves to maintain cell turgidity during drought stress, which is critical for sustaining cellular functions under short-term drought stress.

Cellular hydration and turgidity is largely controlled by the endogenous accumulation of compatible solutes under dehydration stress (Blum and Ebercon, 1981). In this study, naturally produced GB was quantified, which was below $20 \mathrm{mg} \cdot \mathrm{g}^{-1}$ under well-watered conditions, and increased only by $15 \%$ in response to drought stress $\left(23 \mathrm{mg} \cdot \mathrm{g}^{-1}\right)$ in plants without exogenous GB treatment (Fig. 3), which may not be sufficient for stress defense (Ashraf and Foolad, 2007; Rhodes and Hanson, 1993). Exogenous application of GB resulted in a 6.5 -fold

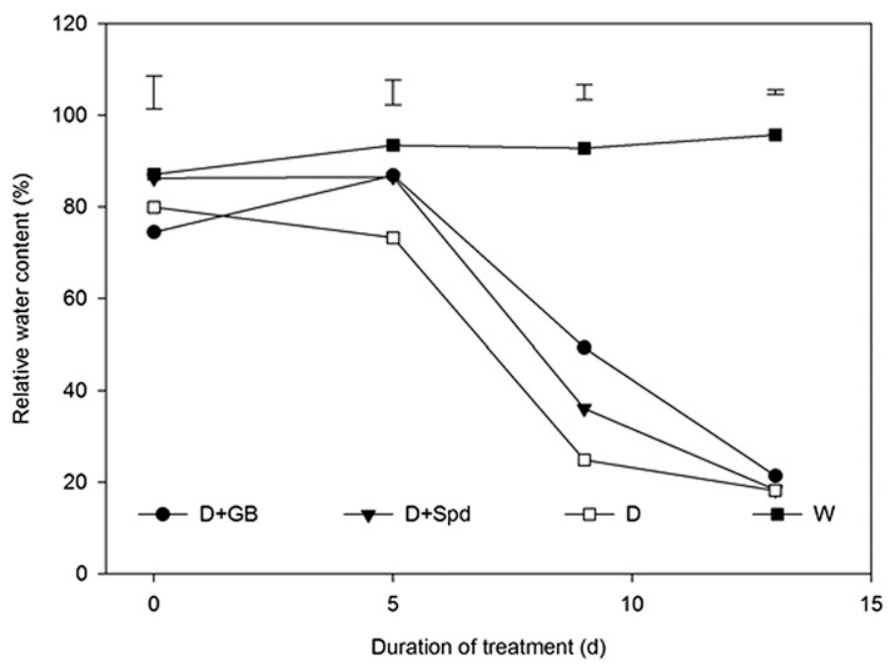

Fig. 2. Leaf relative water content of creeping bentgrass under well-watered (W) and drought stress without (D) and with glycine betaine (D + GB) or spermidine (Spd; D + Spd) treatments. Drought stress was imposed on 12 June $2014(0 \mathrm{~d})$. Vertical bars at the bottom are least significant difference values $(P=0.05)$ for cultivar comparisons at a given day of treatment.

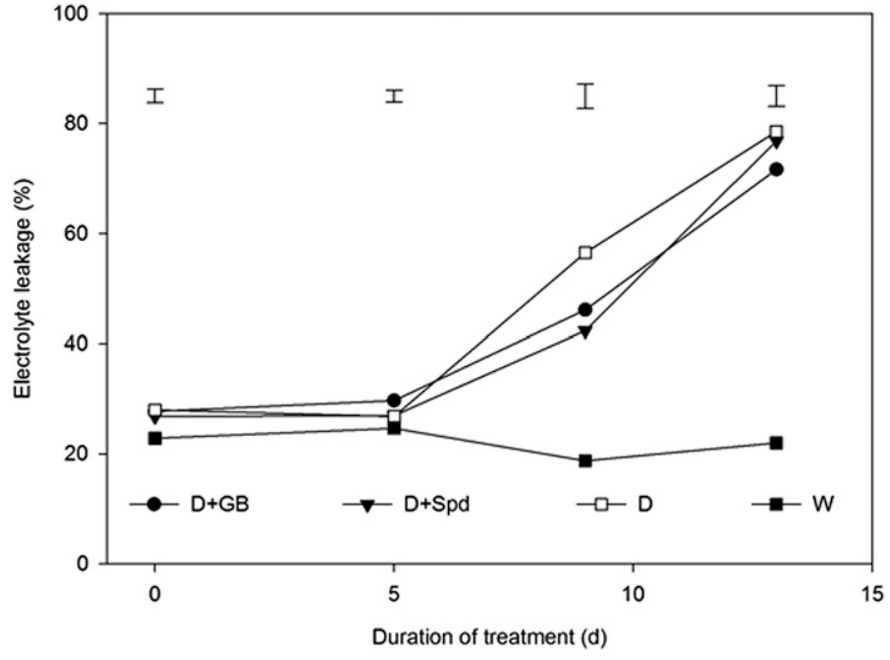

Fig. 3. Leaf electrolyte leakage of creeping bentgrass under well-watered (W) and drought stress without (D) and with glycine betaine $(D+G B)$ or spermidine (Spd; D + Spd) treatments. Drought stress was imposed on 12 June $2014(0 \mathrm{~d})$. Vertical bars at the bottom are least significant difference values $(P=0.05)$ for cultivar comparisons at a given day of treatment.

increase in the endogenous $\mathrm{GB}$ content $\left(148 \mathrm{mg} \cdot \mathrm{g}^{-1}\right)$ in plants exposed to drought stress (Fig. 3). Foliar-applied GB can penetrate into leaves within $1 \mathrm{~h}$ of application and is transported from leaves to roots and other organs within $1 \mathrm{~h}$, contributing to improved stress tolerance (Mäkelä et al., 1996, 1998). Although it is not clear how GB enter the leaves, through stomata and/or the epidermal cells, it was found that including surfactants in the spray solution of GB enhanced its penetration into the leaf; GB is xylem-phloem-mobile and primarily transported in phloem to other organs (Mäkelä et al., 1996).

Endogenous Spd content declined by $25 \%$ under drought stress in creeping bentgrass without the exogenous Spd treatment. The exogenous application of Spd however caused a significant increase (by 30\%) in endogenous Spd content. Spd application also caused 10\% increase in GB content under drought stress compared with untreated plants. Our results suggested that the highly enriched endogenous GB or Spd in leaves could lead to the growth and physiological effects of exogenous application of those compounds on improving drought tolerance in creeping bentgrass that could not naturally produce sufficient amount of those stress-protective solutes.

The accumulation of compatible solutes in plant cells is positively correlated with the level of capacity of OA (Chaves et al., 2003). High capacity of OA in leaf during drought stress exhibited high drought tolerance in many plant species, including turfgrasses (DaCosta and Huang, 2006; Qian and Fry, 1997; White et al., 1992). Glycine betaine and polyamines are considered major compatible solutes for OA (Ashraf and Foolad, 2007; Rhodes and Hanson, 1993). In this study, OA in leaves of well-watered plants was maintained at a low level $(0.05 \mathrm{MPa})$ during the experimental period (Fig. 4). The OA level increased under drought stress in all treatments. A significant OA level was observed in plants treated with GB during the entire drought period compared with the untreated plants under drought stress. However, exogenous application of Spd had no significant effects on OA in creeping bentgrass (Fig. 4). These results suggested that the positive effects of GB on improving drought tolerance could be related to their involvement 
in OA, whereas Spd was not a major contributor to OA in creeping bentgrass.

The maintenance of cellular membrane integrity is also a key factor for plant survival of drought stress that can interrupt membranes through oxidative damages of membrane lipids or cause changes in membrane chemical or structural or properties (Zhang and Kirkham, 1996). Electrolyte leakage is a widely used parameter for the estimation of membrane stability, which is negatively correlated with whole-plant stress tolerance (Jespersen et al., 2013; Marcum, 1998; Rachmilevitch et al., 2006). In this study, well-watered plants maintained low leaf EL (below 24.6\%) throughout the duration of the study, whereas the other four treatments

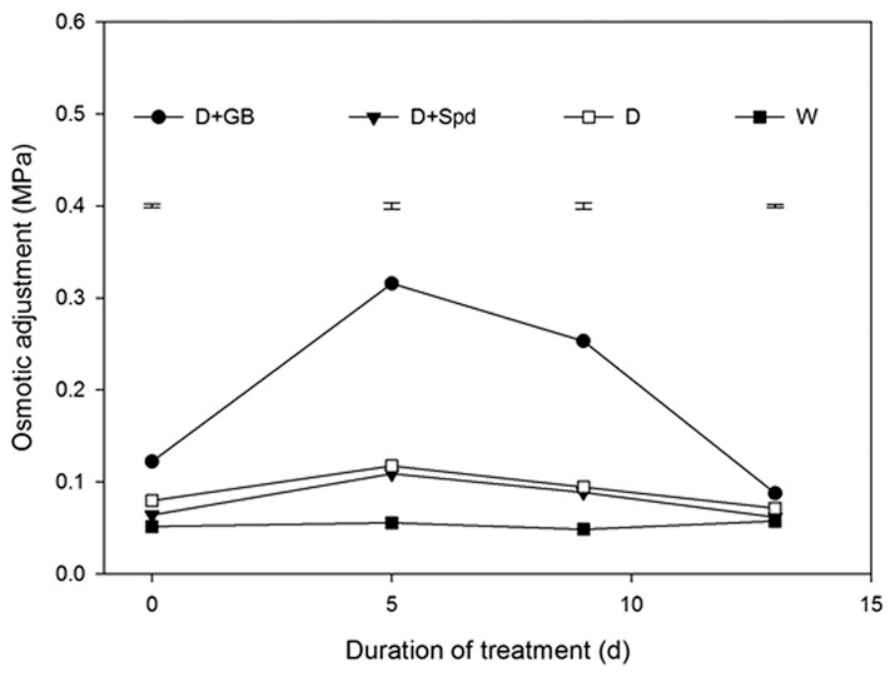

Fig. 4. Osmotic adjustment of creeping bentgrass under well-watered (W) and drought stress without (D) and with glycine betaine (D + GB) or spermidine $(\mathrm{Spd} ; \mathrm{D}+\mathrm{Spd})$ treatments. Drought stress was imposed on 12 June 2014 (0 d). Vertical bars at the bottom are least significant difference values $(P=0.05)$ for cultivar comparisons at a given day of treatment.

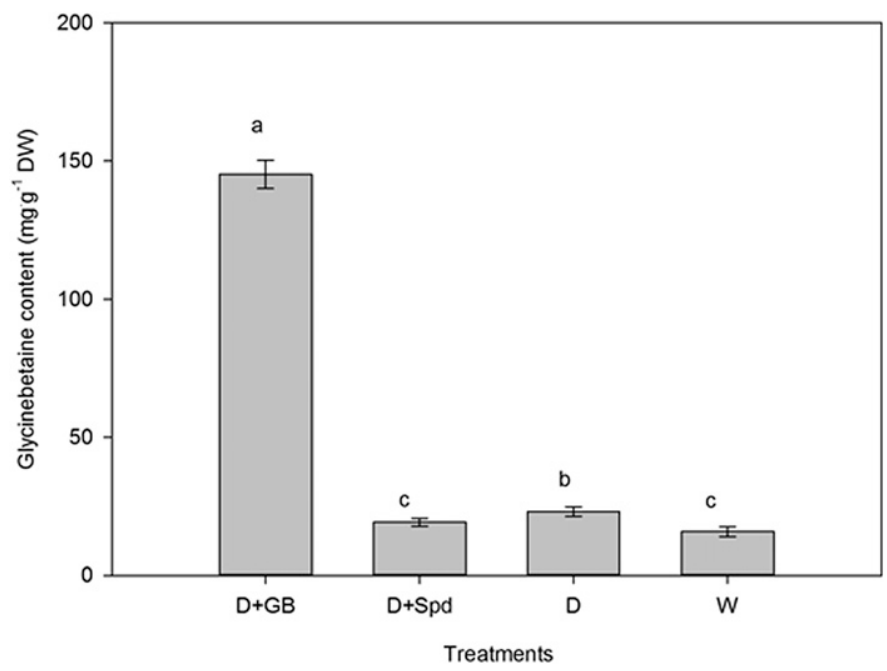

Fig. 5. The content of glycine betaine (GB) of creeping bentgrass under wellwatered conditions (W) and at $9 \mathrm{~d}$ of drought stress without (D) and with GB $(\mathrm{D}+\mathrm{GB})$ or spermidine $(\mathrm{Spd} ; \mathrm{D}+\mathrm{Spd})$ treatments. Columns marked with different letters indicate significant differences among genotypes for each parameter based on least significant difference test $(P=0.05)$. exhibited increases in leaf EL with the duration of drought stress (Fig. 5). Significantly lower EL was detected in Spdtreated plants at $9 \mathrm{~d}$ of drought and in GB-treated plants at 5, 9, and $13 \mathrm{~d}$ of drought compared with the untreated plants. The reduction in EL by GB or Spd has also been reported in other plant species (Quan et al., 2004; Yamada et al., 2007). Our results indicated that GB or Spd had protective effects on cell membranes of creeping bentgrass from drought damages, with GB having longer (13 d) effects than Spd $(9 \mathrm{~d})$. The mechanisms by which GB and Spd protect membranes from drought damages are still unknown. Those compounds may interact with phospholipids and proteins in the membrane to stabilize membrane structures.

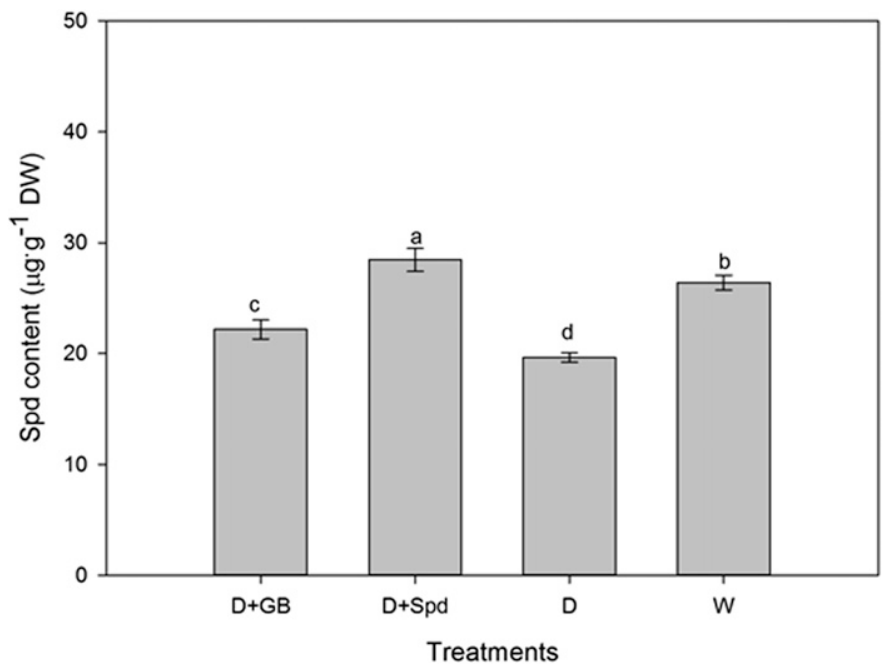

Fig. 6. The content of spermidine ( $\mathrm{Spd}$ ) of creeping bentgrass under wellwatered conditions (W) and at $9 \mathrm{~d}$ of drought stress without (D) and with glycine betaine $(\mathrm{D}+\mathrm{GB})$ or $\mathrm{D}+$ Spd treatments. Columns marked with different letters indicate significant differences among genotypes for each parameter based on least significant difference test $(P=0.05)$.

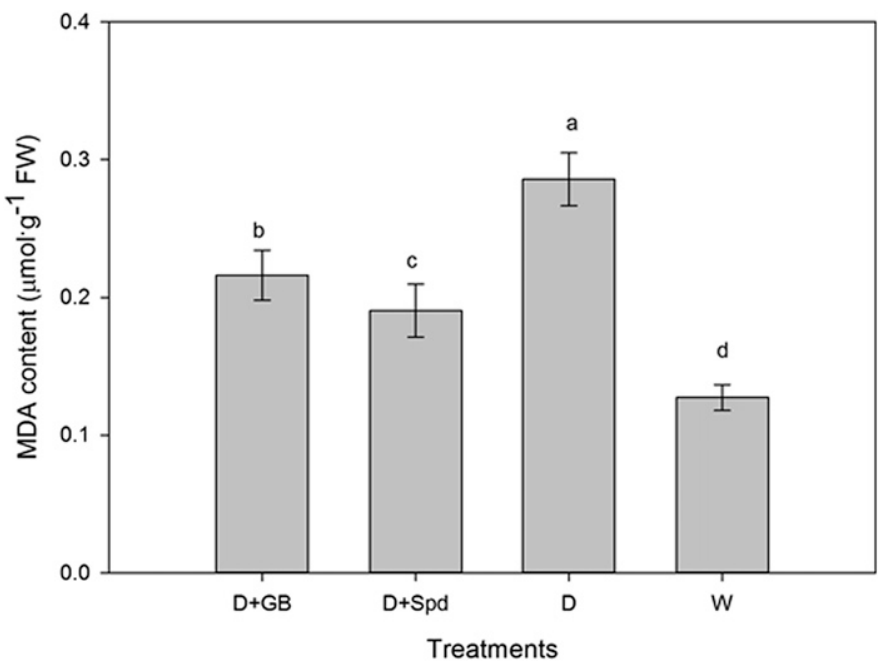

Fig. 7. The content of malondialdehyde (MDA) of creeping bentgrass under well-watered conditions (W) and at $9 \mathrm{~d}$ of drought stress without (D) and with glycine betaine $(\mathrm{D}+\mathrm{GB})$ or spermidine $(\mathrm{Spd} ; \mathrm{D}+\mathrm{Spd})$ treatments. Columns marked with different letters indicate significant differences among genotypes for each parameter based on least significant difference test $(P=0.05)$. 

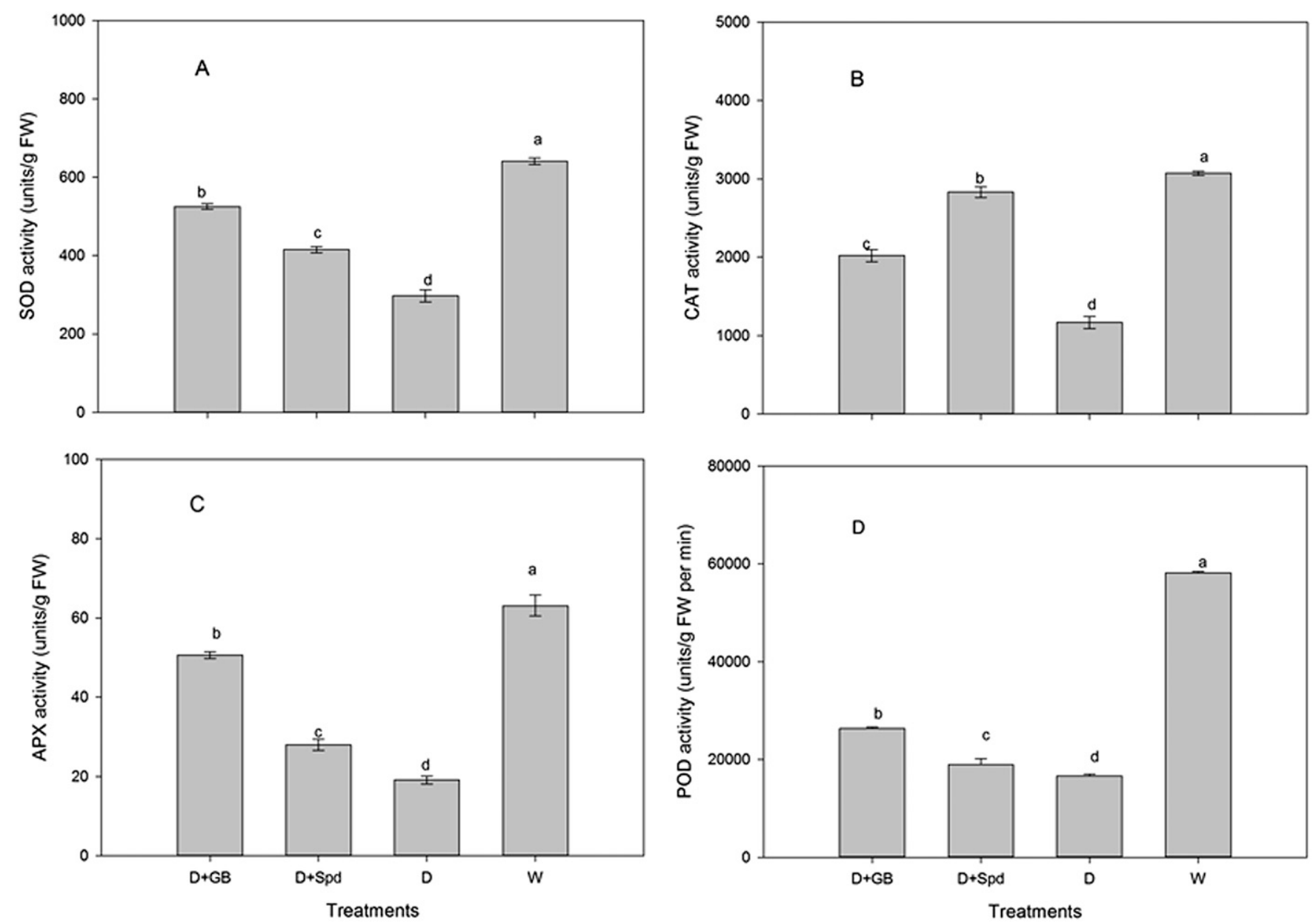

Fig. 8. The activities of (A) superoxide dismutase (SOD), (B) catalase (CAT), (C) ascorbate peroxidase (APX), and (D) peroxidase (POD) of creeping bentgrass under well-watered conditions (W) and at $9 \mathrm{~d}$ of drought stress without (D) and with glycine betaine (D + GB) or spermidine (Spd; D + Spd) treatments. Columns marked with different letters indicate significant differences among genotypes for each parameter based on least significant difference test $(P=0.05)$.

Antioxidant enzymes play key roles in preventing lipid peroxidation of cellular membranes and maintaining membrane stability (Chakraborty and Pradhan, 2011, 2012; Zhang and Kirkham, 1996). Leaf MDA content increased under drought stress in all treatments compared with the wellwatered control, whereas the exogenous application of GB and Spd significantly reduced MDA content in creeping bentgrass exposed to drought stress (Fig. 6). The activity of all antioxidant enzymes decreased under drought stress (Fig. 7). Plants treated with GB or Spd had significantly greater activities of SOD, POD, CAT, and APX than untreated plants under drought stress, with the most pronounced increases for APX $(165 \%$ higher $)$ in GB-treated plants and for CAT $(143 \%$ higher) in Spd-treated plants (Fig. 8). Enhanced activity of antioxidant enzymes by exogenous GB or SPd has also been reported in other plant species under salt stress (Hoque et al., 2008; Islam et al., 2009) or drought stress (Farooq et al., 2009; $\mathrm{Li}$ et al., 2016). Although the positive effects of GB and Spd on antioxidant enzyme activities are well known, whether GB or Spd directly or indirectly regulates those enzymes is not clear. Nevertheless, data from this study indicated that exogenous application of GB and Spd could improve the antioxidant defense system and maintain the membrane stability in creeping bentgrass exposed to drought stress, specifically with GB being most effective influencing APX, and Spd having most pronounced effects on CAT.

In summary, the improved drought tolerance by exogenous GB could be due to its contribution to OA by significant accumulation of endogenous GB and activation of antioxidant enzymes with the greatest effects on APX. Exogenous application of Spd did not cause increases in leaf OA despite of the increased endogenous accumulation, but significantly enhanced antioxidant enzyme activities, with the most pronounced effects on CAT. This study demonstrated that GB and Spd differentially affected $\mathrm{OA}$ and activated different antioxidant defense pathways, protecting plants from drought damages in creeping bentgrass. The underlying molecular mechanisms of how GB and Spd differentially affect antioxidant potential and OA deserve further investigation.

\section{Literature Cited}

Amri, E. and A.R. Shahsavar. 2010. Response of lime seedlings (Citrus aurantifolia L.) to exogenous spermidine treatments under drought stress. Austral. J. Basic Appl. Sci. 4:4483-4489.

Ashraf, M. and M.R. Foolad. 2007. Roles of glycine betaine and proline in improving plant abiotic stress resistance. Environ. Expt. Bot. 59:206-216. 
Blum, A. and A. Ebercon. 1981. Cell membrane stability as a measure of drought and heat tolerance in wheat. Crop Sci. 21:43-47.

Bouchereau, A., A. Aziz, and F. Larher. 1999. Polyamines and environmental challenges: Recent developments. Plant Sci. 140:103-125.

Burgess, P. and B. Huang. 2013. Effects of sequential application of plant growth regulators and osmoregulants on drought tolerance of creeping bentgrass. Crop Sci. 54:837-844.

Chakraborty, U. and B. Pradhan. 2011. Drought stress-induced oxidative stress and antioxidative responses in four wheat (Triticum aestivum L.) varieties. Arch. Agron. Soil Sci. 58:1-14.

Chakraborty, U. and B. Pradhan. 2012. Oxidative stress in five wheat varieties (Triticum aestivum L.) exposed to water stress and study of their antioxidant enzyme defense system, water stress responsive metabolites and $\mathrm{H}_{2} \mathrm{O}_{2}$ accumulation. Braz. J. Plant Physiol. 24:117-130.

Chance, B., A.C. Maehly, and B. Chance. 1955. Assay of catalases and peroxidases. Methods Enzymol. 55:764-775.

Chaves, M.M., J.P. Maroco, and J.S. Pereira. 2003. Understanding plant responses to drought-From genes to the whole plant. Funct. Plant Biol. 30:239-264.

DaCosta, M. and B. Huang. 2006. Changes in carbon partitioning and accumulation patterns during drought and recovery for colonial bentgrass, creeping bentgrass, and velvet bentgrass. J. Amer. Soc. Hort. Sci. 131:484-490.

Demiral, T. and I. Türkan. 2004. Does exogenous glycine betaine affect antioxidative system of rice seedlings under $\mathrm{NaCl}$ treatment? J. Plant Physiol. 161:1089-1100.

Dhindsa, R.S., P. Plumb-Dhindsa, and T. Thorpe. 1981. Leaf senescence: Correlated with increased levels of membrane permeability and lipid peroxidation, and decreased levels of superoxide dismutase and catalase. J. Expt. Bot. 32:93-101.

Farooq, M., S.M.A. Basra, and A. Wahid. 2008. Physiological role of exogenously applied glycine betaine to improve drought tolerance in fine grain aromatic rice (Oryza sativa L.). J. Agr. Crop Sci. 194:325-333.

Farooq, M., A. Wahid, and D.J. Lee. 2009. Exogenously applied polyamines increase drought tolerance of rice by improving leaf water status, photosynthesis and membrane properties. Acta Physiol. Plant. 31:937-945.

Gupta, N., S.K. Thind, and N.S. Bains. 2013. Glycine betaine application modifies biochemical attributes of osmotic adjustment in drought stressed wheat. Plant Growth Regulat. 72:221-228.

Heath, R.L. and L. Packer. 1968. Photoperoxidation in isolated chloroplasts. I. Kinetics and stoichiometry of fatty acid peroxidation. Arch. Biochem. Biophys. 125:189-198.

Hoagland, D.R. and D.I. Arnon. 1950. The water-culture method for growing plants without soil. California Agr. Expt. Sta. Circ. 347.

Hoque, M.A., M.N. Banu, and Y. Nakamura. 2008. Proline and glycinebetaine enhance antioxidant defense and methylglyoxal detoxification systems and reduce $\mathrm{NaCl}$-induced damage in cultured tobacco cells. J. Plant Physiol. 165:813-824.

Jespersen, D., W. Meyer, and B. Huang. 2013. Physiological traits and genetic variations associated with drought and heat tolerance in creeping bentgrass. Intl. Turf Res. J. 12:459-464.

Islam, M.M., M.A. Hoque, and E. Okuma. 2009. Exogenous proline and glycinebetaine increase antioxidant enzyme activities and confer tolerance to cadmium stress in cultured tobacco cells. J. Plant Physiol. 166:1587-1597.

Kubiś, J. 2003. Polyamines and "scavenging system": Influence of exogenous spermidine on catalase and guaiacol peroxidase activities, and free polyamine level in barley leaves under water deficit. Acta Physiol. Plant. 23:335-341.

Li, Z., Y. Zhang, and X. Zhang. 2016. The alterations of endogenous polyamines and phytohormones induced by exogenous application of spermidine regulate antioxidant metabolism, metallothionein and relevant genes conferring drought tolerance in white clover. Environ. Expt. Bot. 124:22-38.

Liu, J., X.J. Ji, and Y.L. Liu. 2002. High performance liquid chromatography method for measuring polyamine content in plant tissue. Plant Physiol. Commun. 38:596-598.

Mäkelä, P., K. Jokinen, M. Kontturi, P. Peltonen-Sainio, E. Pehu, and S. Somersalo. 1998. Foliar application of glycine betaine - a novel product from sugar beet - as an approach to increase tomato yield. Ind. Crops Prod. 7:139-148.

Mäkelä, P., P. Peltonen-Sainio, K. Jokinen, E. Pehu, H. Setälä, R. Hinkkanen, and S. Somersalo. 1996. Uptake and translocation of foliar-applied glycinebetaine in crop plants. Plant Sci. 121:221-230.

Marcum, K. 1998. Cell membrane thermostability and whole-plant heat tolerance of kentucky bluegrass. Crop Sci. 38:1214-1218.

Nilsen, E.T. and D.M. Orcutt. 1996. Physiology of plants under stress: Abiotic factors. Wiley, New York, NY.

Okuma, E., Y. Murakami, and Y. Shimoishi. 2004. Effects of exogenous application of proline and betaine on the growth of tobacco cultured cells under saline conditions. Soil Sci. Plant Nutr. 50:1301-1305.

Qian, Y. and J.D. Fry. 1997. Water relations and drought tolerance of four turfgrasses. J. Amer. Soc. Hort. Sci. 122:129-133.

Quan, R., M. Shang, H. Zhang, Y. Zhao, and J. Zhang. 2004. Engineering of enhanced glycine betaine synthesis improves drought tolerance in maize. Plant Biotechnol. 2:477-486.

Rachmilevitch, S., M. DaCosta, and B. Huang. 2006. Physiological and biochemical indicators for abiotic stress tolerance, p. 321-356. In: B. Huang (ed.). Plant-environment interaction. CRC Press, Boca Raton, FL.

Rhodes, D. and A.D. Hanson. 1993. Quaternary ammonium and tertiary sulfonium compounds in higher plants. Annu. Rev. Plant Physiol. 44:357-384.

Shi, H.T., T.T. Ye, and Z.L. Chan. 2013. Comparative proteomic and physiological analyses reveal the protective effect of exogenous polyamines in the bermudagrass (Cynodon dactylon) response to salt and drought stresses. J. Proteome Res. 12:4951-4964.

Shukla, V., Y. Ma, and E.M. Merewitz. 2015. Creeping bentgrass responses to drought stress and polyamine application. J. Amer. Soc. Hort. Sci. 140:102-107.

Turgeon, A.J. 2008. Turfgrass management. 8th ed. Pearson Prentice Hall, Upper Saddle River, NJ.

Wang, X., Y. Wu, and L.M. Wang. 2010. Determination of betaine in fruits of Lycium barbarum L. by solid phase extraction and high performance liquid chromatography. Food Sci. 8:199-201.

White, R.H., M.C. Engelke, S.J. Morton, and B.A. Ruemmele. 1992. Competitive turgor maintenance in tall fescue. Crop Sci. 32:251-256.

$\mathrm{Xu}, \mathrm{Q}$. and B. Huang. 2004. Antioxidant metabolism associated with summer leaf senescence and turf quality decline for creeping bentgrass. Crop Sci. 44:553-560.

Yamaguchi, K., Y. Takahashi, T. Berberich, A. Imai, T. Takahashi, A.J. Michael, and T. Kusano. 2007. A protective role for the polyamine spermine against drought stress in Arabidopsis. Biochem. Biophys. Res. Commun. 352:486-490.

Yang, Z., J. Yu, E. Merewitz, and B. Huang. 2012. Differential effects of abscisic acid and glycine betaine on physiological responses to drought and salinity stress for two perennial grass species. J. Amer. Soc. Hort. Sci. 137:96-106.

Yin, Z.P., S. Li, and J. Ren. 2014. Role of spermidine and spermine in alleviation of drought-induced oxidative stress and photosynthetic inhibition in Chinese dwarf cherry (Cerasus humilis) seedlings. Plant Growth Regulat. 74:209-218.

Zhang, J. and M.B. Kirkham. 1996. Enzymatic responses of the ascorbate-glutathione cycle to drought in sorghum and sunflower plants. Plant Sci. 113:139-147. 